\section{ECCOMAS}

\section{Proceedia}

COMPDYN 2021

$8^{\text {th }}$ ECCOMAS Thematic Conference on Computational Methods in Structural Dynamics and Earthquake Engineering M. Papadrakakis, M. Fragiadakis (eds.) Streamed from Athens, Greece, 28 - 30 June 2021

\title{
A DISPLACEMENT-BASED DESIGN PROCEDURE OF VISCOUS DAMPED STEEL EXOSKELETONS FOR THE SEISMIC RETROFITTING OF RC FRAMED BUILDINGS
}

\author{
Fabio Mazza $^{1}$ and Egidio Mollo ${ }^{2}$ \\ ${ }^{1}$ Dipartimento di Ingegneria Civile, Università della Calabria \\ 87036, Rende (Cosenza), Italy \\ e-mail: fabio.mazza@unical.it \\ ${ }^{2}$ Dipartimento di Ingegneria Civile, Università della Calabria \\ 87036, Rende (Cosenza), Italy \\ e-mail: egidio.mollo@outlook.it
}

\begin{abstract}
The dissipative exoskeleton (DEX), an external framed structure equipped with a damped bracing system and rigidly coupled to the existing building is to be retrofitted, may be more convenient than a dissipative endoskeleton (DEN), constituted of braces connecting adjacent storeys and equipped with dissipative devices. Aim of the present work is the proposal of a displacement-based design procedure of the DEX based on the use of overdamped elastic response spectra, which could prove a valuable tool for practitioners. The DEX includes concentrically braced chevron frames, with pinned joints, and damped bracing systems, incorporating fluid viscous dampers (FVDs). Elastic-linear behaviour of steel frame members and nonlinear pure viscous dashpot for FVDs are hypothesized. A six-storey archetype located in $L$ 'Aquila (Italy), representative of many reinforced concrete $(R C)$ framed buildings designed for moderate seismic loads, is to be retrofitted in a high risk-seismic region. The building is regular in plan, with five longitudinal bays (main fronts corresponding to the north-and south-facing façades) and three bays in the transversal one (east-and west-facing façades without apertures). Nonlinear static analysis using the software OpenSEES is preliminarily carried out, to investigate the seismic vulnerability of the existing building. $R C$ frame members are modelled with lumped plasticity elements, with flexure- or shear-controlled momentchord rotation at critical end sections, while the shear behaviour of the beam-column joints is modelled by means of a scissor model. Interventions with DEXs are designed at the life-safety (LS) limit state, considering parallel (DEX.Pa) and perpendicular (DEX.Pe) dispositions, running around all four façades, and mixed disposition (DEX.Mi), as an enlargement on the eastern and western sides only. In order to demonstrate effectiveness of the retrofitting interventions, nonlinear dynamic analyses of the bare $(F)$ and coupled (DEXF) structures are carried out considering records scaled in line with a high-risk seismic region.
\end{abstract}

Keywords: RC Framed Buildings, Dissipative Steel Exoskeletons, Nonlinear Fluid Viscous Dampers, Seismic Retrofitting, Design Procedure. 


\section{INTRODUCTION}

The dissipative endoskeleton (DEN) constituted of steel braces supporting devices dissipating energy by means of different mechanisms (metallic yielding, friction sliding, fluid orificing, viscoelastic deformation, phase transformation of metals) offers certain advantages (e.g. ease of inspection and replacement, low maintenance costs) in comparison to traditional retrofitting solutions [1, 2], but it can also induce downsides: e.g. notable increase in the axial load transmitted to columns and foundations; indirect costs associated with the temporary relocation of residents; service interruption during installation. On the other hand, the dissipative exoskeleton (DEX), an external steel framed structure equipped with a damped bracing system, rigidly coupled to the existing building but with an own foundation, exhibits many advantages [3]: the indirect costs associated with downtime during retrofitting are eliminated; the creation of new housing space and the opportunity for an energetic retrofit of the building envelope are possible; the complete reversibility is guaranteed.

Three typological choices are possible depending on the distributive (e.g. available space) and energetic (e.g. thermal loss) features along the perimeter [4-6]: a partial or uniform dissipative exoskeleton, parallel (DEX.Pa) and perpendicular (DEX.Pe) positioned to the façades to which it is connected through standard shear and axial links, respectively; a mixed DEX (DEX.Mi), where DEX.Pa and DEX.Pe are placed on the same façade. It should be noted that DEX.Pa always provides additional torsional stiffness to the original scheme, while the added spatiality in the façades resulting from DEX.Pe allows the creation of new housing space, partially or totally covering the retrofitting costs by means of the increased real estate value, upgrades vertical accessibility (e.g. stairwells and lifts) as well as horizontal private or collective circulation (e.g. balconies and living spaces). However, the increased useful space provided by DEX.Pe corresponds to a non-negligible additional mass of the exoskeleton structure compared to the total mass of the building, thereby inducing seismic loads higher than those corresponding to the DEX.Pa arrangement. As this last solution supports gravity loads due to their self-weight only, large overturning moments induced by the horizontal seismic loads may lead to tensile axial force in its foundation. Both solutions provide the opportunity for an energetic retrofit of the building envelope, but compared to the DEN not only the dissipative bracing system but also the new steel exoskeleton needs to be designed.

A design procedure of DEXs incorporating nonlinear fluid viscous dampers (FVDs) is implemented in this study, which focuses on displacement as the key sizing parameter and employs overdamped elastic response spectra. The procedure is a reformulated version of an approach recently derived for DEN systems [7-11], conceived in such way as to make a clear distinction between the design of a steel exoskeleton (i.e. mass, stiffness and strength) and a dissipative bracing system (i.e. added damping), and an extension including nonlinear FVDs. In the subsequent sections the proposed design procedure is applied for the seismic retrofitting of a six-storey reinforced concrete (RC) archetype in L'Aquila (Italy), representative of many buildings designed for moderate seismic loads prior to the 2008-2018 code changes [12]. Interventions with DEXs are designed at the life-safety (LS) limit state, considering three alternatives: i) parallel disposition running around all four façades (DEX.Pa), with a distance from the existing structure set to suit the new foundation and to allow the opening of windows; ii) perpendicular disposition running around all four façades (DEX.Pe), with a floor slab defining new spaces increasing the wellbeing of the inhabitants along main fronts with north and south exposure; iii) parallel-perpendicular mixed disposition (DEX.Mi), as an enlargement on the eastern and western transversal sides only where energy saving measures could be added. Nonlinear analyses are carried out using the software OpenSEES [13], in order to provide insights into the strength and weaknesses of the examined configurations. 


\section{DISPLACEMENT-BASED-DESIGN PROCEDURE OF THE VISCOUS DAMPED DISSIPATIVE EXOSKELETON}

A four-step double-iteration design procedure of the DEX is proposed, whose design parameters are: target performance displacement evaluated through nonlinear static analysis of the existing structure; properties of the nonlinear fluid viscous dampers (FVDs), in terms of maximum equivalent viscous damping ratio $\left(\xi_{\mathrm{v}, \mathrm{DB} 0}\right)$ and velocity exponent $(\beta)$; seismic loads. On the other hand, final unknown parameters are mass, stiffness and strength properties of the steel exoskeleton and damping constant of the FVDs.

By referring to two coupled equivalent single-degree-of-freedom (SDOF) systems shown in Figure 1, representing the original frame (F, black line) with an infinitely rigid but nondissipative connection to a DEX (blue line), relevant design parameters are mass and stiffness ratios

$$
\alpha_{m}=m_{e, D E X} / m_{e, F} ; \quad \alpha_{K}=K_{e, D E X} / K_{e, F}
$$

and uncoupled equivalent damping ratios $\xi_{\mathrm{F}}$ and $\xi_{\mathrm{DEX}}$. Equivalent mass of the SDOF system representing the original frame can be evaluated by multiplying the first-mode (horizontal) components $\left(\phi_{1}, \phi_{2}, . ., \phi_{\mathrm{n}}\right)$ by the corresponding floor masses $\left(\mathrm{m}_{1, \mathrm{~F}}, \mathrm{~m}_{2, \mathrm{~F}}, . ., \mathrm{m}_{\mathrm{n}, \mathrm{F}}\right)$

$$
m_{e, F}=\sum_{i=1}^{n}\left(m_{i, F} \cdot \phi_{i}\right), \quad\left(\phi_{n}=1\right)
$$

while equivalent (secant) stiffness depends on base shear $\left(\mathrm{V}_{\mathrm{p}, \mathrm{F}}^{*}\right)$ at the performance displacement $\left(d^{*}\right)$

$$
K_{e, F}=V_{p, F}^{*} / d_{p}^{*}
$$

resulting from the nonlinear static analysis of the original structure. A double iteration process is required because for an assigned value of $\xi_{\mathrm{DEX}}$ and known value of $\xi_{\mathrm{F}}$, both corresponding to the assigned displacement demand $\mathrm{d}_{\mathrm{p}}^{*}$, the corresponding coupled total damping ( $\left.\xi_{\mathrm{DEXF}}\right)$ is function of $\alpha_{\mathrm{K}}$ which in turns depends on the unknown $\alpha_{\mathrm{m}}$.

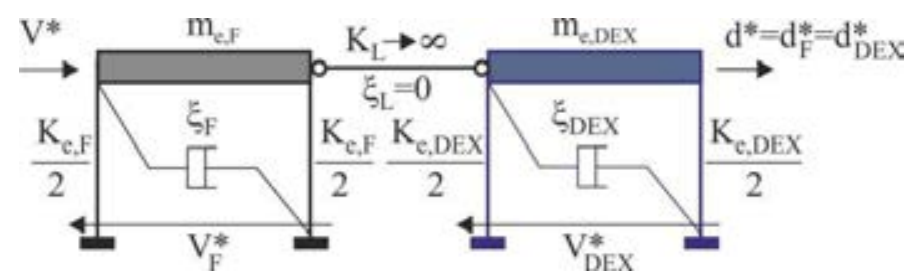

Figure 1. DEXF system as coupling of two equivalent SDOF systems.

The four steps of the proposed design procedure are discussed below. It should be noted that the design procedure requires internal (step 3) and external (steps 3-4) iteration loops related to the stiffness $\left(\alpha_{\mathrm{k}}{ }^{(.)}\right)$and mass $\left(\alpha_{\mathrm{m}}{ }^{(.)}\right)$ratios, respectively. An initial approximation of these ratios is assigned in step 2 (i.e. $\alpha_{\mathrm{k}}{ }^{(0)}$ and $\alpha_{\mathrm{m}}{ }^{(0)}$ ), and then a sequence of iteration loops is performed until convergence to the correct values is attained (i.e. $\alpha_{\mathrm{k}}{ }^{(\mathrm{i})} \approx \alpha_{\mathrm{k}}{ }^{(\mathrm{i}-1)}$ and $\alpha_{\mathrm{m}}{ }^{(\mathrm{i})} \approx \alpha_{\mathrm{m}}{ }^{(\mathrm{i}-1)}$ ).

\subsection{Properties of the SDOF system equivalent to the original frame (F)}

Once base shear $\left(V_{F}\right)$ versus roof-storey displacement $(d)$ capacity curve of the original framed structure is evaluated from pushover analysis and transformed into the capacity (bilinear) curve $\left(\mathrm{V}^{*}-\mathrm{d}^{*}\right)$ of an equivalent SDOF system [14], the equivalent viscous damping due to hysteresis $\xi_{\mathrm{h}, \mathrm{F}}$ at the performance displacement $\left(\mathrm{d}_{\mathrm{p}}{ }^{*}\right)$ can be calculated 


$$
\xi_{h, F}(\%)=\kappa \cdot\left(63.7 \frac{\left(\mu_{F}-1\right) \cdot\left(1-r_{F}\right)}{\mu_{F} \cdot\left[1+r_{F} \cdot\left(\mu_{F}-1\right)\right]}\right)
$$

as function of the following parameters (Figure $2 b$ ): ductility demand $\mu_{\mathrm{F}}\left(=\mathrm{d}_{\mathrm{p}} / \mathrm{d}_{\mathrm{y}, \mathrm{F}}\right.$, being $\mathrm{d}_{\mathrm{y}, \mathrm{F}}$ the yield displacement); stiffness hardening ratio $\left(\mathrm{r}_{\mathrm{F}}\right)$; reduction factor $(\kappa)$, depending on the degrading response of $\mathrm{RC}$ frame members $[10,11]$. An inherent elastic viscous damping of the framed structure (commonly, $\xi_{\mathrm{v}, \mathrm{F}}=5 \%$ ) can be also defined (Figure $2 \mathrm{a}$ ).
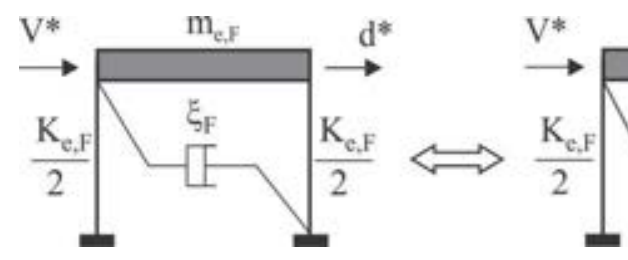

(a)

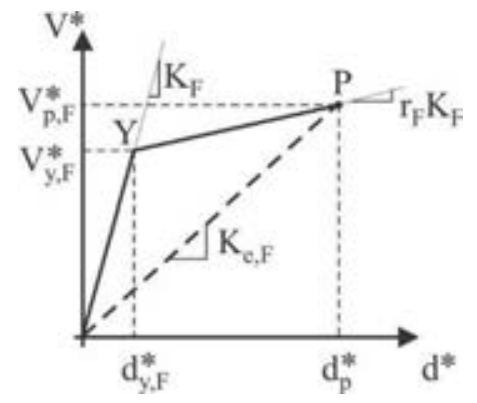

(b)

Figure 2. SDOF system equivalent to the original structure (a) and its response (b) idealized as bilinear.

\subsection{Properties of the SDOF system equivalent to the dissipative exoskeleton (DEX)}

Starting from the assumption that the stiffness $\left(\mathrm{K}_{\mathrm{B}}\right)$ of the brace used to install the damper in the exoskeleton (EX) is large enough to eliminate the added stiffness of the FV damped brace (i.e. $\mathrm{K}_{\mathrm{e}, \mathrm{DB}}=0$ ), the effective (secant) stiffness of the DEX is equal only to the EX part (Figure 3)

$$
K_{e, D E X}=K_{e, E X}
$$

and its unknown value is assumed as the effective (secant) stiffness of the original frame multiplied by an initial value $\left(\alpha_{\mathrm{K}}^{(0)}\right)$ of the stiffness ratio

$$
K_{e, D E X}^{(0)}=\alpha_{K}^{(0)} \cdot K_{e, F}
$$

Similarly, the effective mass of the equivalent DEX is obtained on the basis of an initial value $\left(\alpha_{\mathrm{m}}{ }^{(0)}\right)$ of the mass ratio

$$
m_{e, D E X}^{(0)}=\alpha_{m}^{(0)} \cdot m_{e, F}
$$

as function of the effective mass of the SDOF equivalent to the original frame (see Equation (2)).

With regard to the nonlinear FVD, the force developed in the damper is function of the damping exponent ( $\beta<1$, with $\beta=1$ corresponding to linear viscous property)

$$
F_{V D}=C_{N L} \cdot \operatorname{sign}(v) \cdot|v|^{\beta}=F_{V D B}
$$

where $\mathrm{C}_{\mathrm{NL}}$ is the nonlinear damping coefficient, $\mathrm{v}$ is the relative velocity between the end sections of the device and sign(v) is the sign function. Moreover, the equivalent viscous damping ratio for one cycle of harmonic vibration can be expressed as [1, 15]

$$
\xi_{v, D B}(\%)=\frac{\lambda \cdot C_{N L} \cdot \omega_{e, D E X}^{\beta} \cdot d_{p}^{\beta-1}}{2 \pi \cdot K_{D E X}}
$$


being

$$
\lambda=2^{2+\beta} \cdot \frac{\Gamma^{2} \cdot\left(1+\frac{\beta}{2}\right)}{\Gamma \cdot(2+\beta)}
$$

and $\Gamma$ the gamma function. It is easy to verify that the equivalent viscous damping ratio corresponding to $d_{p}$ can be computed in terms of an assigned maximum value ( $\left.\xi_{\mathrm{v}, \mathrm{DB} 0}\right)$ at the limit of elastic behaviour for the original frame:

$$
\xi_{v, D B}(\%)=\xi_{v, D B O}(\%) \cdot\left(\mu_{F}\right)^{\beta-1}
$$

For completeness, an inherent elastic damping of the exoskeleton (e.g. $\xi_{\mathrm{v}, \mathrm{EX}}=2 \%$ is generally used for steel structures) is also defined in Figure $3 \mathrm{a}$.

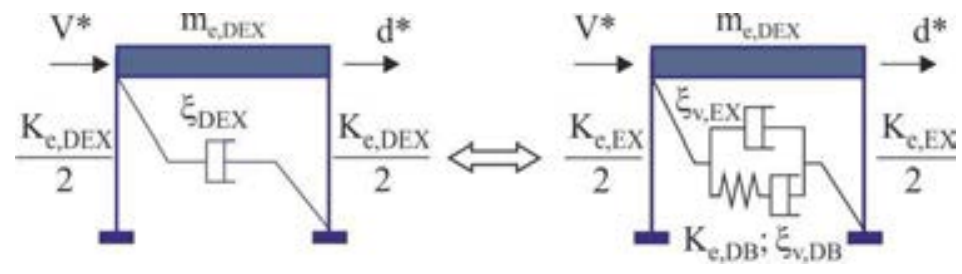

(a)

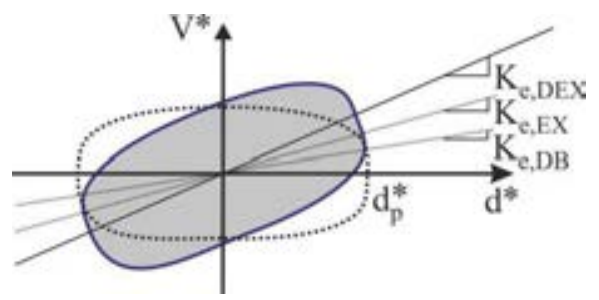

(b)

Figure 3. SDOF system equivalent to the DEX (a) and its non-elliptic hysteresis curve (b).

\subsection{Properties of the SDOF system equivalent to the frame with dissipative exoskeleton (DEXF)}

The equivalent viscous damping of the in-parallel system constituted of frame (F) and dissipative exoskeleton (DEX) is function of the stiffness ratio $\alpha_{\mathrm{K}}{ }^{(.)}\left(=\alpha_{\mathrm{K}}{ }^{(0)}\right.$ at the first iteration loop)

$$
\xi_{D E X F}^{(.)}(\%)=\xi_{v, F}+\xi_{v, E}+\frac{\xi_{h, F}+\xi_{v, D B} \cdot \alpha_{K}^{(.)}}{1+\alpha_{K}^{(.)}}
$$

where $\xi_{\mathrm{h}, \mathrm{F}}$ and $\xi_{\mathrm{v}, \mathrm{DB}}$ are calculated in steps 2.1 and 2.2 , respectively. Then, the effective period of DEXF $\left(\mathrm{T}^{(. .)}\right.$e,DEXF) is evaluated with reference to the curve of the overdamped displacement-acceleration response spectra corresponding to $\xi^{(. .)}$DEXF and the performance displacement $d_{p}^{*}$ (Figure 4). Moreover, the acceleration design value $\left(a^{*}{ }^{(. .)}\right)$can be determined as y-coordinate by the same curve.

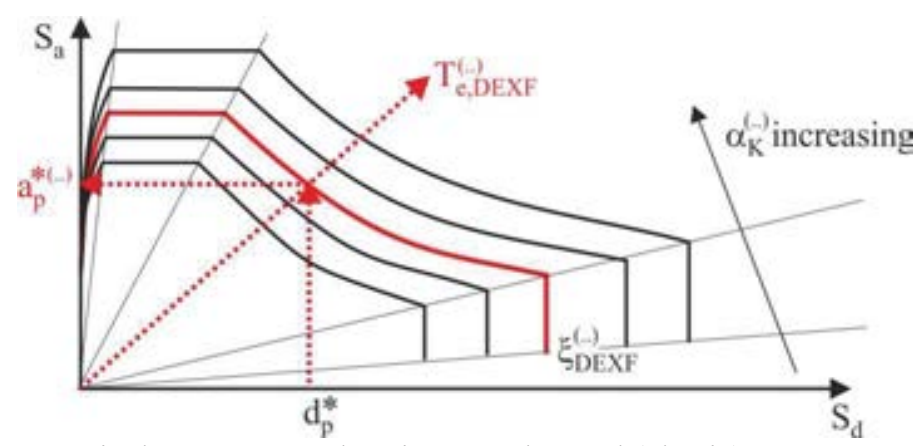

Figure 4. Displacement-acceleration overdamped (elastic) response spectra. 
Once the mass of the DEXF is calculated

$$
m_{e, D E X F}^{(\cdot)}=m_{e, F}+m_{e, D E X}^{(\cdot)}=\left(1+\alpha_{m}^{(.)}\right) \cdot m_{e, F}
$$

the effective stiffness can be obtained as

$$
K_{e, D E X F}^{(.)}=\frac{4 \cdot \pi^{2} \cdot m_{e, D E X F}^{(.)}}{\left(T_{e, D E X F}^{(.)}\right)^{2}}
$$

Finally, an updated value of the stiffness ratio is determined

$$
\alpha_{K}^{(.)}=K_{e, D E X}^{(.)} / K_{e, F}
$$

where

$$
K_{e, D E X}^{(.)}=K_{e, D E X F}^{(.)}-K_{e, F}
$$

As a consequence, an iterative procedure internal to the current step is needed for the solution of Equations (12)-(16) until a final stiffness ratio value is attained.

\subsection{Properties of the dissipative exoskeleton (DEXF) for the MDOF system}

The proportional stiffness criterion [16] allows evaluation of the internal design forces of the steel EX considering the distribution of the lateral loads resulting from the first-mode shape (i.e. $\left.\phi_{\mathrm{i}}=\phi_{\mathrm{i}, \mathrm{F}}=\phi_{\mathrm{i}, \mathrm{EX}}, \mathrm{i}=1, . ., \mathrm{n}\right)$ that remains practically unchanged after the insertion of the EX (Figure 5)

$$
F_{E X, i}^{(.)}=\frac{m_{i, F} \cdot \phi_{i}}{\sum_{i=1}^{n}\left(m_{i, F} \cdot \phi_{i}\right)} V_{d, E X}^{(.)}
$$

where it is proved that the base-shear is equal to

$$
V_{d, E X}^{(.)}=\frac{V_{d, D E X F}^{(.)} \cdot \alpha_{K}^{(.)}}{1+\alpha_{K}^{(.)}}=\left(1+\alpha_{m}^{(.)}\right) \cdot m_{e, F} \cdot a_{p}^{(.)} \cdot \frac{\alpha_{K}^{(.)}}{1+\alpha_{K}^{(.)}}=V_{d, D E X}^{(.)}
$$

It is worth mentioning that base shear expressed by Equation (18) depends on the mass ratio $\alpha_{\mathrm{m}}^{(.)}$which is initially unknown. As a consequence, an external iterative procedure needs to be carried out on steps 2.3 and 2.4 for the solution of Equations (12)-(18), until a final mass ratio value is attained.

$$
\alpha_{m}^{(.)}=m_{e, D E X}^{(.)} / m_{e, F}=\sum_{i=1}^{n}\left(m_{i, D E X}^{(\cdot)} \cdot \phi_{i}\right) / m_{e, F},\left(\phi_{n}=1\right)
$$

Finally, the distribution of the damping coefficients for the nonlinear FVDs is assumed proportional to the design storey shear of DEX, on the assumption that reduced efficiency of the FVDs generally observed on the upper storeys is related to slower interstorey velocities than those in the lower storeys, through the following expression [17]

$$
C_{N L, t o t, j}=\frac{(2 \pi)^{3-\beta} \cdot\left(d_{p}\right)^{I-\beta} \cdot \xi_{v, D B}}{\left(T_{1, D E X F}\right)^{2-\beta}} \cdot \frac{S_{j} \cdot \sum_{i=1}^{n}\left(m_{i, D E X F} \cdot \phi_{i}^{2}\right)}{\lambda \cdot \sum_{i=1}^{n}\left[S_{i} \cdot f_{i}^{l+\beta} \cdot\left(\phi_{i}-\phi_{i-1}\right)^{1+\beta}\right]}, j=1, \ldots, n
$$

where $f_{i}$ is the magnification factor of the dampers, depending on their configuration in each storey ( $\mathrm{f}_{\mathrm{i}}=1$ for chevron configuration of the FVDB), and $\mathrm{T}_{1, \mathrm{DEXF}}$ is the fundamental vibration 
period of DEXF. It is clear that, at each storey the shear force is proportional to parameter [18]

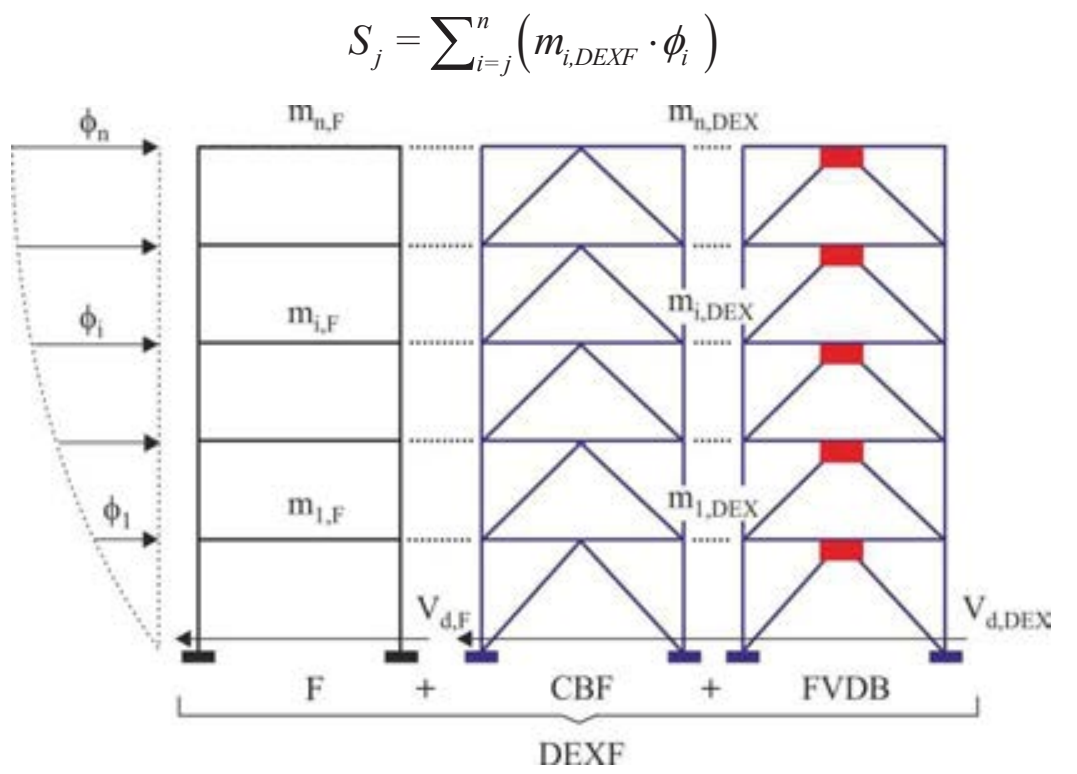

Figure 5. MDOF system representing the original frame (F) combined with DEX.

\section{LAYOUT AND RETROFITTING OF THE TEST STRUCTURE}

An RC framed building located in L'Aquila, representative of the Italian residential housing stock constructed prior to the 2008-2018 code changes [12], is considered as test structure for the numerical investigation. The building is regular in elevation (Figure 6b), while torsion is moderate so the building can be considered also as regular in plan although the staircase is asymmetrically placed along the $\mathrm{X}$ direction and bays with different lengths are considered along the $\mathrm{Y}$ direction (Figure 6a).

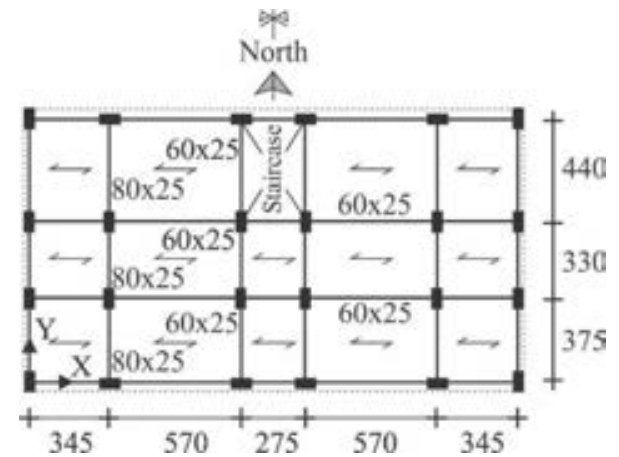

(a) Plan

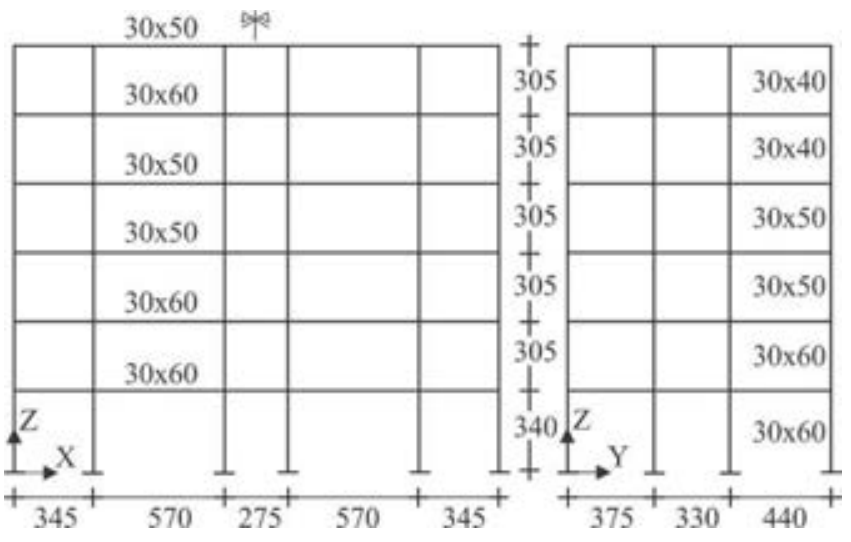

(b) Elevation.

Figure 6. Layout of the archetype (unit in $\mathrm{cm}$ ).

Cross-section of columns, with the orientation shown in Figure 6a, and deep beams, for perimeter frames and knee configuration of the staircase, are tapered along the building height but constant at each storey (Figure 6b); on the contrary, all internal beams are flat with a constant cross-section at all storeys but this is not the same for different bays (Figure 6a). Masonry infills contribute to the dead load, with a weight of $3.5 \mathrm{kN} / \mathrm{m}^{2}$ along the perimeter façades reduced as function of the percentage of apertures. A simulated design of the test structure is 
carried out in line with the Italian code DM86 [19], for the seismic loads at the time corresponding to the medium-risk seismic zone and typical subsoil class. Provisions of the Italian code DM92 [20] are also satisfied, assuming the following gravity loads: dead loads of 4.8 $\mathrm{kN} / \mathrm{m}^{2}$, on the roof, and $6.3 \mathrm{kN} / \mathrm{m}^{2}$, on the other floors; live loads of $2.2 \mathrm{kN} / \mathrm{m}^{2}$, on the roof (snow), $2 \mathrm{kN} / \mathrm{m}^{2}$, on the other floors, and $4 \mathrm{kN} / \mathrm{m}^{2}$ for the staircase. Further details can be found in [12]. Mean compressive cylindrical strength of concrete and steel yield strength equal to $25 \mathrm{MPa}$ and $435 \mathrm{MPa}$ are assumed, respectively, in the design of the test structure.

Modal and uniform nonlinear static analyses of the original building are preliminarily performed by the OpenSEES platform [13]. A lumped plasticity model is considered for RC frame members, with a trilinear moment-chord rotation backbone curve modified on the basis of the ultimate shear capacity in the event of brittle failure [21, 22]. The shear behaviour of the exterior and interior beam-column joints is modelled by means of a scissor model, with rigid end offsets and double node, considering shear failure prior to or together with yielding of the longitudinal steel reinforcement of beams [23, 24]. Capacity curves reported in Figure 7 represent roof drift ratio (i.e. $\mathrm{d}_{\text {top }} / \mathrm{H}_{\text {tot }}$, $\mathrm{d}_{\text {top }}$ and $\mathrm{H}_{\text {tot }}$ being the horizontal top displacement and total height) versus normalized base shear (i.e. $\mathrm{V}_{\text {base }} / \mathrm{W}_{\text {tot }}, \mathrm{W}_{\text {tot }}$ being the total seismic weight). Note that pushover curves referring to the positive and negative loading directions are nearly identical, especially in the $\mathrm{X}$ direction (Figure 7a), due to the structural symmetry. Maximum strength is always achieved in the $\mathrm{Y}$ direction (Figure $7 \mathrm{~b}$ ), depending on the effects of the staircase and in-plan orientation of the cross-sections of all interior columns and most of the exterior ones (Figure 6a), while maximum deformability is attained in the $\mathrm{X}$ direction (Figure 7a), where flat interior beams with reduced section are placed. Attention will be focused on the modal capacity curves, that show a maximum $\mathrm{V}_{\text {base }} / \mathrm{W}_{\text {tot }}$ ratio roughly between 0.15 (X direction) and 0.2 (Y direction) when one of the aforementioned failure mechanisms is attained for structural elements and joints.

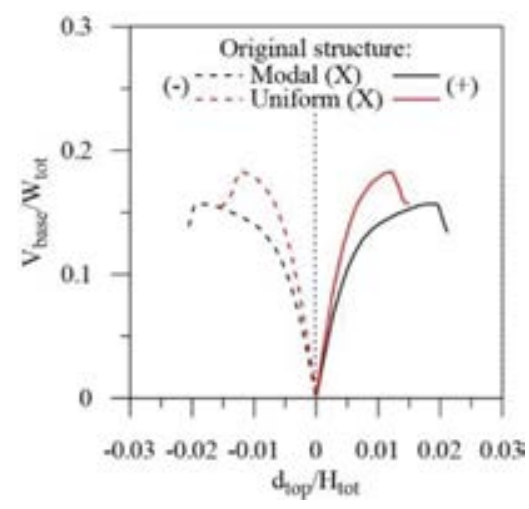

(a) X direction.

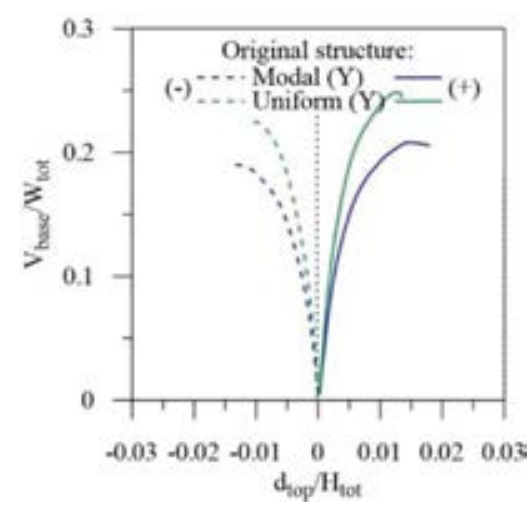

(b) Y direction.

Figure 7. Comparison of pushover curves for modal and uniform lateral load patterns.

Different dissipative exoskeletons are designed at the life-safety (LS) ultimate limit state provided by NTC18 [25] for a residential building (functional class II, coefficient of use $\mathrm{C}_{\mathrm{U}}=1.0$ and expected life of 50 years) located in L'Aquila $\left(13.40^{\circ}\right.$ longitude and $42.35^{\circ}$ latitude). Current high-risk seismic zone designation (peak ground acceleration on rock, $\mathrm{a}_{\mathrm{g}}=0.261 \mathrm{~g}$ ) and moderately-soft subsoil (class $\mathrm{C}$, site amplification factor $\mathrm{S}=1.33$ ) are assumed. In particular, concentrically chevron braced frames (CBFs) and chevron braces with fluid viscous dampers (FVDBs) are arranged in three configurations: i) DEX.Pa (Figure 8), configured in adhesion (parallel) to all façades, considerably limiting the external dimensions in the case of urban planning restrictions; ii) DEX.Pe (Figure 9), as an enlargement of the entire building plan, creating additional (perpendicular) living space only along main fronts with 
north and south exposure as these are the sides with apertures; iii) DEX.Mi (Figure 10), where DEX.Pa and DEX.Pe are placed as an enlargement on the eastern and western sides without apertures to satisfy both thermal and seismic requirements. The seismic demand for the design of the DEXs assumes as performance objective an elastic behaviour of the original structure (i.e. $d_{\mathrm{p}}=\mathrm{d}_{\mathrm{y}, \mathrm{F}}$ and $\xi_{\mathrm{h}, \mathrm{F}}=0$ ), while the amount of supplemental viscous damping required to limit maximum displacement within this target value is assumed equal to $\xi_{\mathrm{v}, \mathrm{DB} 0}=20 \%$ and elastic viscous damping of the exoskeleton is omitted.

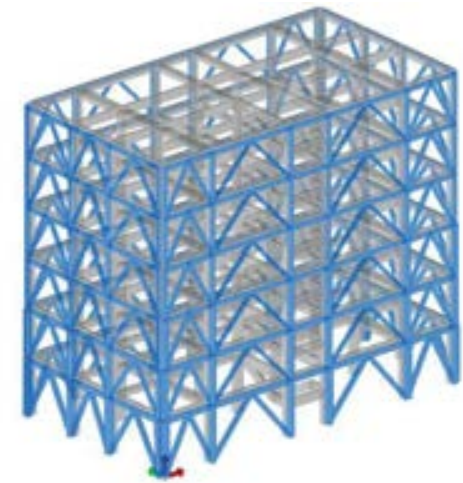

(a) Three-dimensional view.

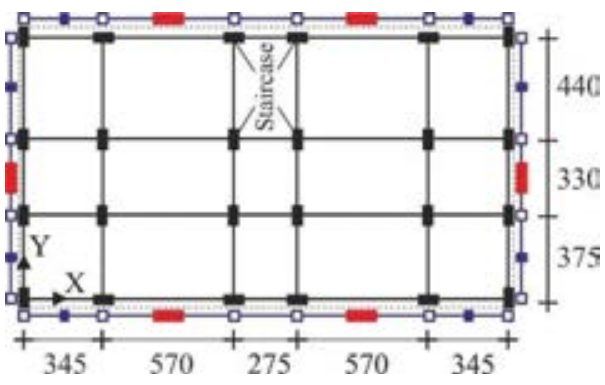

(b) Plan.

Figure 8. Dissipative exoskeleton parallel (DEX.Pa) to the original building (unit in $\mathrm{cm}$ ): $\square-\square$ chevron brace; $\square-\square$ viscous damped chevron brace.

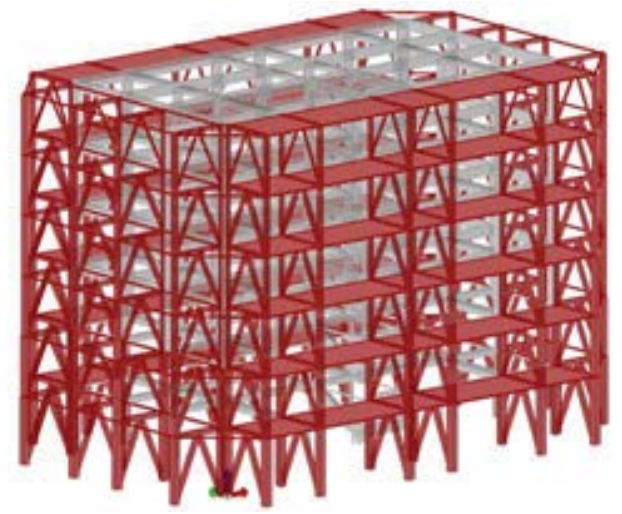

(a) Three-dimensional view.

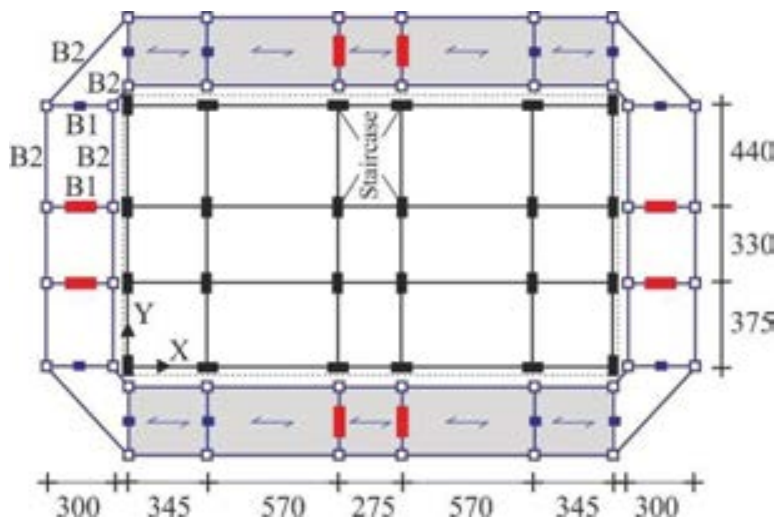

(b) Plan.

Figure 9. Dissipative exoskeleton perpendicular (DEX.Pe) to the original building (unit in $\mathrm{cm}$ ): $\square-\square$ chevron brace; $\square-\square$ viscous damped chevron brace.

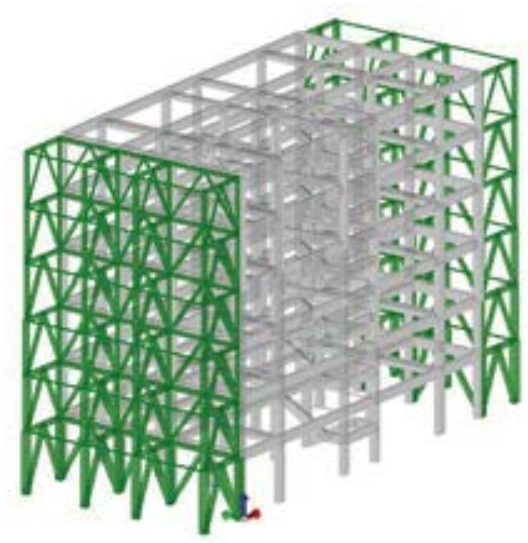

(a) Three-dimensional view.

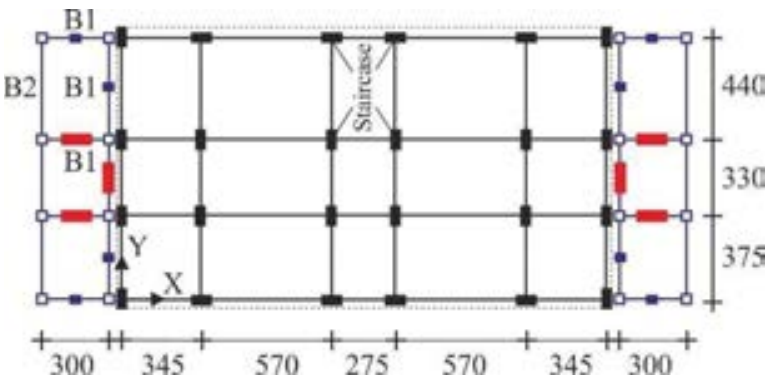

(b) Plan.

Figure 10. Dissipative exoskeleton with a mixed configuration (DEX.Mi) around the original building (unit in $\mathrm{cm}): \square \longrightarrow \square$ chevron brace; $\square-\square-\square$ viscous damped chevron brace. 
The stiffening contribution of the chevron braces arranged in series with the FVDBs is not considered while nonlinear viscous behaviour, with an exponent $\beta$ equal to 0.7 , is assumed for the FVDs. The gravity loads considered for the composite deck with horizontal bracing of DEX.Pe, having a length of 3 metres (see grey areas in Figure 9b), are represented by a dead load of $3.73 \mathrm{kN} / \mathrm{m}^{2}$ and a live load of $2 \mathrm{kN} / \mathrm{m}^{2}$. The design of DEXs is performed in accordance with the four-step procedure presented below, and main parameters of the equivalent SDOF systems are reported in Tables $1 \mathrm{a}$ and $1 \mathrm{~b}$ with reference to the $\mathrm{X}$ and $\mathrm{Y}$ directions, respectively.

\begin{tabular}{|c|c|c|c|c|c|c|c|c|c|}
\hline Structure & $\mathrm{K}_{\mathrm{e}, \mathrm{F}}$ & $\mathrm{m}_{\mathrm{e}, \mathrm{F}}$ & $\xi_{\mathrm{h}, \mathrm{F}}$ & $\alpha_{\mathrm{m}}$ & $\alpha_{\mathrm{K}}$ & $\xi_{\mathrm{v}, \mathrm{DB}}$ & $\xi_{\text {DEXF }}$ & $\mathrm{T}_{\mathrm{e}, \mathrm{DEXF}}$ & $\mathrm{V}_{\mathrm{d}, \mathrm{DEXF}}$ \\
\hline DEXF.Pa & 213 & 931 & 0 & 0.034 & 6.55 & 20 & 22.4 & 0.487 & 4678 \\
\hline DEXF.Pe & 213 & 931 & 0 & 0.289 & 8.33 & 20 & 22.9 & 0.489 & 5778 \\
\hline DEXF.Mi & 213 & 931 & 0 & 0.042 & 6.60 & 20 & 22.4 & 0.487 & 4709 \\
\hline
\end{tabular}

Table 1a. Properties of the SDOF system equivalent to DEXF along the $\mathrm{X}$ direction (units in $\mathrm{cm}, \mathrm{kN}, \mathrm{t}$ and $\mathrm{s}$ ).

\begin{tabular}{|c|c|c|c|c|c|c|c|c|c|}
\hline Structure & $\mathrm{K}_{\mathrm{e}, \mathrm{F}}$ & $\mathrm{m}_{\mathrm{e}, \mathrm{F}}$ & $\xi_{\mathrm{h}, \mathrm{F}}$ & $\alpha_{\mathrm{m}}$ & $\alpha_{\mathrm{K}}$ & $\xi_{\mathrm{v}, \mathrm{DB}}$ & $\xi_{\mathrm{DEXF}}$ & $\mathrm{T}_{\mathrm{e}, \mathrm{DEXF}}$ & $\mathrm{V}_{\mathrm{d}, \mathrm{DEXF}}$ \\
\hline DEXF.Pa & 414 & 923 & 0 & 0.034 & 6.55 & 20 & 22.4 & 0.347 & 4638 \\
\hline DEXF.Pe & 414 & 923 & 0 & 0.289 & 8.32 & 20 & 22.9 & 0.349 & 5728 \\
\hline DEXF.Mi & 414 & 923 & 0 & 0.042 & 6.60 & 20 & 22.4 & 0.347 & 4668 \\
\hline
\end{tabular}

Table 1b. Properties of the SDOF system equivalent to DEXF along the $\mathrm{Y}$ direction (units in $\mathrm{cm}, \mathrm{kN}, \mathrm{t}$ and $\mathrm{s}$ ).

The tubular square cross-sections selected for primary beams (i.e. typology B1), columns and chevron braces of the CBFs are assumed ductile, in line with class 1 of NTC18. These elements satisfy the ultimate limit states for strength and buckling under the horizontal seismic loads evaluated through Equations (17) and (18). Moreover, secondary (i.e. typology B2) beams with circular (DEX.Pe) and square (DEX.Mi) cross sections are also considered in order to obtain a spatial truss exoskeleton, for which class 3 prevents local buckling until yield strength is reached in a compression fibre. The dimensions obtained for the member crosssections, assuming yield strength equal to $275 \mathrm{MPa}$, and damping coefficients of nonlinear FVDs are reported in Table 2 (DEX.Pa), Table 3 (DEX.Pe) and Table 4 (DEX.Mi). It should be noted that FVDs are inserted on chevron braces with the same dimensions as those of the CBFs.

\begin{tabular}{|c|c|c|c|c|c|c|}
\hline \multirow{2}{*}{ Storey } & \multirow{2}{*}{ Beams } & \multirow{2}{*}{ Columns } & \multicolumn{2}{|c|}{ Chevron braces } & \multicolumn{2}{c|}{$\mathrm{C}_{\text {NL,tot }}$ (FVDs) } \\
\cline { 4 - 6 } & & & X direction & Y direction & X direction & Y direction \\
\hline 1 & $250 \times 8$ & $350 \times 16$ & $220 \times 16$ & $220 \times 16$ & 9999 & 9118 \\
\hline 2 & $250 \times 8$ & $300 \times 12.5$ & $180 \times 12.5$ & $180 \times 12.5$ & 9657 & 8818 \\
\hline 3 & $200 \times 8$ & $260 \times 10$ & $180 \times 10$ & $180 \times 10$ & 8839 & 8092 \\
\hline 4 & $200 \times 8$ & $220 \times 8$ & $180 \times 8$ & $160 \times 10$ & 7438 & 6830 \\
\hline 5 & $200 \times 8$ & $220 \times 8$ & $180 \times 6.3$ & $150 \times 8$ & 5388 & 4976 \\
\hline 6 & $200 \times 8$ & $220 \times 8$ & $160 \times 6.3$ & $150 \times 6.3$ & 2702 & 2513 \\
\hline
\end{tabular}

Table 2. Member cross-sections (mm) and damping coefficient of FVDs (units in kN, s and m) for DEX.Pa.

\begin{tabular}{|c|c|c|c|c|c|c|c|}
\hline \multirow{2}{*}{ Storey } & \multicolumn{2}{|c|}{ Beams } & \multirow{2}{*}{ Columns } & \multicolumn{2}{c|}{ Chevron braces } & \multicolumn{2}{c|}{ CNL,tot $_{\text {(FVDs) }}$} \\
\cline { 2 - 6 } & B1 & B2 & & X direction & Y direction & X direction & Y direction \\
\hline 1 & $350 \times 10$ & $88.9 \times 5$ & $400 \times 20$ & $350 \times 16$ & $300 \times 12.5$ & 8467 & 11545 \\
\hline 2 & $300 \times 10$ & $88.9 \times 5$ & $350 \times 16$ & $260 \times 12.5$ & $260 \times 8$ & 8209 & 11199 \\
\hline 3 & $300 \times 10$ & $88.9 \times 5$ & $300 \times 10$ & $220 \times 12$ & $250 \times 6.3$ & 7619 & 10322 \\
\hline 4 & $200 \times 8$ & $88.9 \times 5$ & $300 \times 10$ & $180 \times 12.5$ & $220 \times 6.3$ & 6533 & 8750 \\
\hline 5 & $200 \times 8$ & $88.9 \times 5$ & $220 \times 8$ & $150 \times 12.5$ & $180 \times 6$ & 4854 & 6421 \\
\hline 6 & $200 \times 8$ & $88.9 \times 5$ & $220 \times 8$ & $140 \times 12$ & $140 \times 6.3$ & 2496 & 3299 \\
\hline
\end{tabular}

Table 3. Member cross-sections ( $\mathrm{mm}$ ) and damping coefficient of FVDs (units in $\mathrm{kN}, \mathrm{s}$ and $\mathrm{m}$ ) for DEX.Pe. 


\begin{tabular}{|c|c|c|c|c|c|c|c|}
\hline \multirow{2}{*}{ Storey } & \multicolumn{2}{|c|}{ Beams } & \multirow{2}{*}{ Columns } & \multicolumn{2}{c|}{ Chevron braces } & \multicolumn{2}{c|}{ C $_{\text {NL,tot }}$ (FVDs) } \\
\cline { 2 - 7 } & B1 & B2 & & X direction & Y direction & X direction & Y direction \\
\hline 1 & $300 \times 10$ & $50 \times 5$ & $400 \times 16$ & $260 \times 16$ & $250 \times 16$ & 8424 & 10753 \\
\hline 2 & $250 \times 10$ & $50 \times 5$ & $300 \times 16$ & $220 \times 12$ & $180 \times 12.5$ & 8178 & 10370 \\
\hline 3 & $250 \times 10$ & $50 \times 5$ & $260 \times 10$ & $200 \times 10$ & $180 \times 10$ & 7560 & 9442 \\
\hline 4 & $200 \times 8$ & $50 \times 5$ & $220 \times 8$ & $150 \times 12$ & $180 \times 8$ & 6443 & 7894 \\
\hline 5 & $200 \times 8$ & $50 \times 5$ & $220 \times 8$ & $120 \times 12.5$ & $150 \times 8$ & 4738 & 5675 \\
\hline 6 & $200 \times 8$ & $50 \times 5$ & $220 \times 8$ & $120 \times 12$ & $150 \times 6.3$ & 2407 & 2821 \\
\hline
\end{tabular}

Table 4. Member cross-sections (mm) and damping coefficient of FVDs (units in $\mathrm{kN}, \mathrm{s}$ and $\mathrm{m}$ ) for DEX.Mi.

\section{NUMERICAL RESULTS}

Nonlinear seismic analysis of the structure before (i.e. original, F) and after (i.e. retrofitted, DEX.Pa, DEX.Pe and DEX.Mi) the insertion of the dissipative exoskeleton is evaluated by the finite element code OpenSEES [13]. Nonlinear fluid viscous dampers are modelled as twoNodeLink elements, assuming nonlinear dashpot and linear spring acting in series without considering the combined flexibility of the supporting brace and FVD. An elastic linear behaviour, equal for tension and compression, is considered for all truss members of the concentrically steel braced frames. The exoskeleton is connected to the RC framed building at each floor level by means of shear and/or axial rigid steel links. Inherent damping $\xi_{\mathrm{v}, \mathrm{F}}=5 \%$ for the $\mathrm{RC}$ framed structure is modelled using mass and tangent stiffness proportional Rayleigh approach, while the contribution of steel exoskeleton is not considered $\left(\xi_{\mathrm{v}, \mathrm{EX}}=0 \%\right)$. Seismic input selection for the bi-directional nonlinear dynamic analyses considers earthquakes taken from the Italian accelerometric archive [26] and NGAwest2 database [27], the latter when records reflecting the NTC18 provisions at the site in question were not available, and scaled to match the LS design response spectrum [28].

Mean values of the maximum base shear are reported in Figure 11 for the original (F) and retrofitted $(\mathrm{DEX}(\mathrm{F})$ and $(\mathrm{DEX}) \mathrm{F}$ referring to parallel $(\mathrm{Pa})$, perpendicular $(\mathrm{Pe})$ and mixed $(\mathrm{Mi})$ steel dissipative exoskeleton and $\mathrm{RC}$ frame, respectively) structures, which are labelled with letter A when resulting from nonlinear time-history analysis.

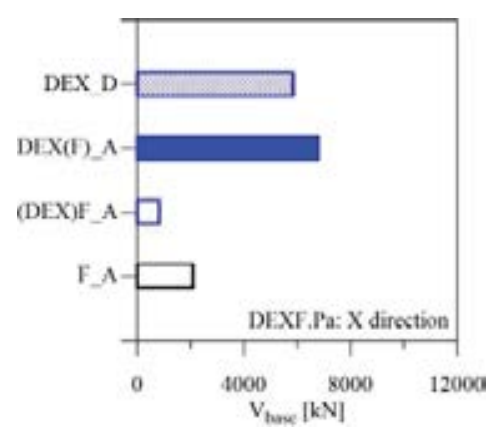

(a)

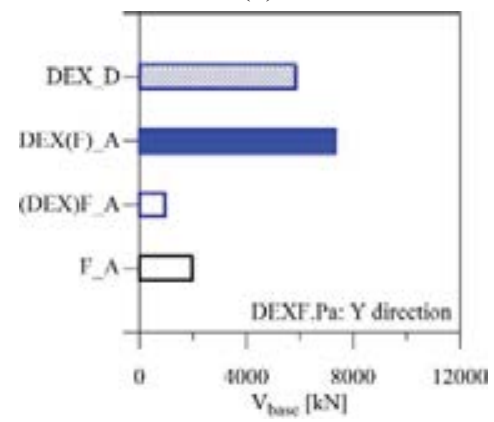

(d)

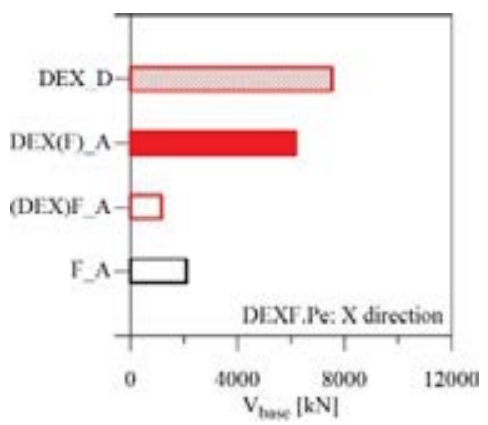

(b)

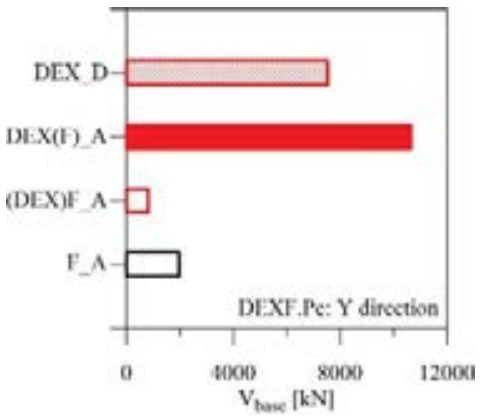

(e)

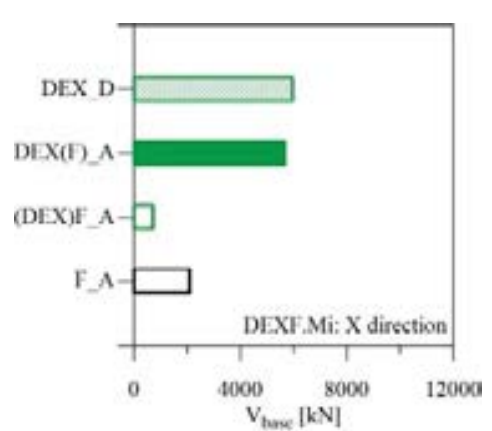

(c)

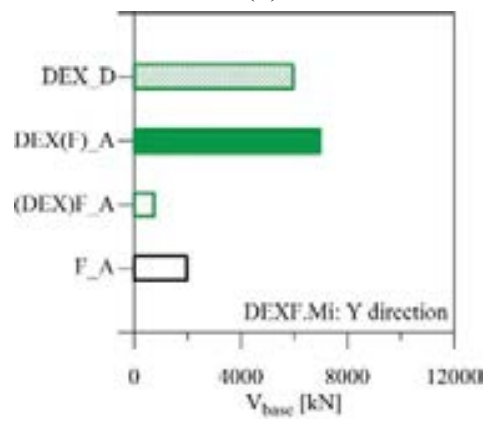

(f)

Figure 11. Seismic demand in terms of base shear for the original (F) and retrofitted (DEXF) structures. 
As a comparison, design values (letter D) of the base shear obtained for DEXs are also reported with reference to DEXF.Pa (Figures 11a,d), DEXF.Pe (Figure 11b,e) and DEX.Mi (Figures 11c,f). The proportion between the base shear corresponding to DEX(F)_A and $(\mathrm{DEX}) \mathrm{F}_{-}$A structural parts highlights a good fit with the design value of the stiffness ratio $\alpha_{\mathrm{K}}$ (see Tables 1a and 1b), thus confirming the reliability of the design procedure of DEXs. This is further demonstrated by the ratio between design (D) and analysis (A) base shear for DEX, whose value falls approximately into the range of $-10 \%$ to $+30 \%$, which represent the lower and upper bound tolerances provided by NTC18 when recorded ground motions are scaled to a certain level of seismic intensity. Evidence of the effectiveness of the proposed retrofitting strategies also results from base shear related to (DEX)F_A, whose value is between one half (Figure 11e) and one third (Figure 11c) of that given to the corresponding F_A.

Afterwards, mean values of the storey drift ratio, defined as drift along the in-plan $X(\Delta x)$ and $\mathrm{Y}\left(\Delta_{\mathrm{Y}}\right)$ directions normalized by the storey height $(\mathrm{h})$, are shown in Figure 12. The original structure (F) exhibits an irregular distribution law of the drift ratio, with higher deformability in the X (Figure 12a) rather than in the Y (Figure 12d) direction. The insertion of DEXs generally ensures a reduction of at least half of the drift demand. The only exception is the top floor where an increase in drift demand referring to $\mathrm{Y}$ is observed for DEX.Pa and DEX.Pe (Figure 12d), though highlighting values less than $0.5 \%$. Among the three viable retrofitting schemes, DEXF.Pa and DEX.Mi turn out to be the best choice parallel to X (Figure 12a) and Y (Figure 12d), respectively. Graphs of horizontal displacement at the floor levels (Figures $12 \mathrm{~b}, \mathrm{e})$ confirm the effectiveness of all configurations of the DEX. The acceleration profiles over the elevation of the building, normalised by gravity acceleration $g$, are displayed in Figures 12c,f. Amplification of acceleration is found in all DEXF systems compared to the original frame, with values increasing towards the upper levels. Moreover, a clear worsening is observed in the Y direction (Figure 12f), where DEX.Pe is the worst solution inducing a threefold increase in top floor acceleration.

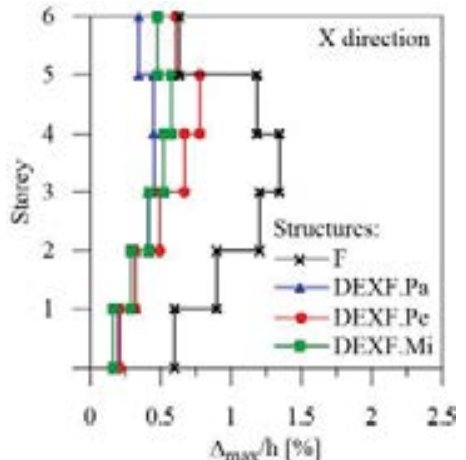

(a)

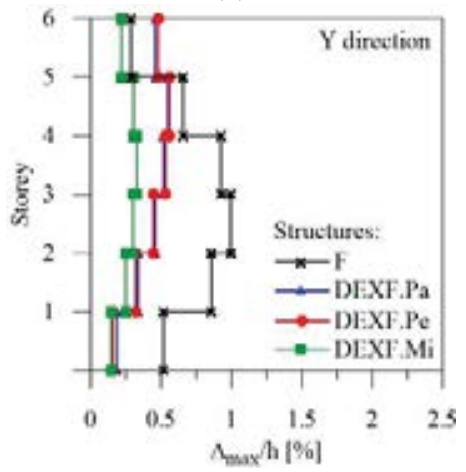

(d)

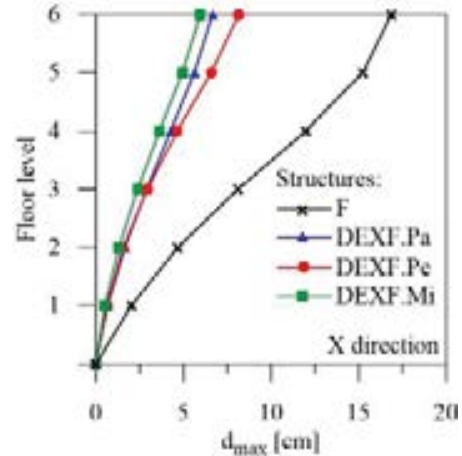

(b)

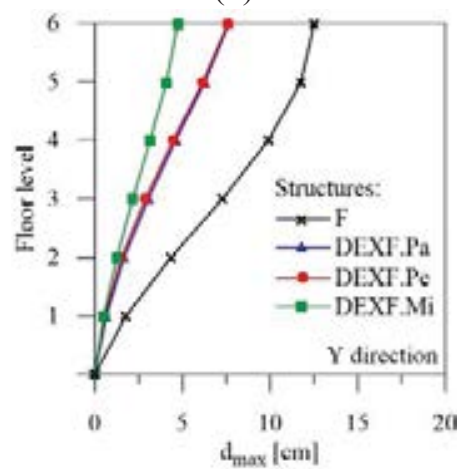

(e)

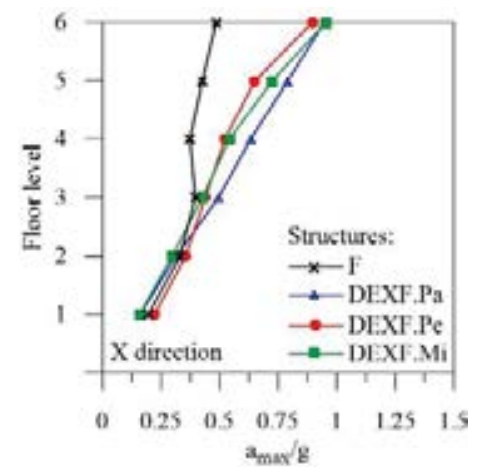

(c)

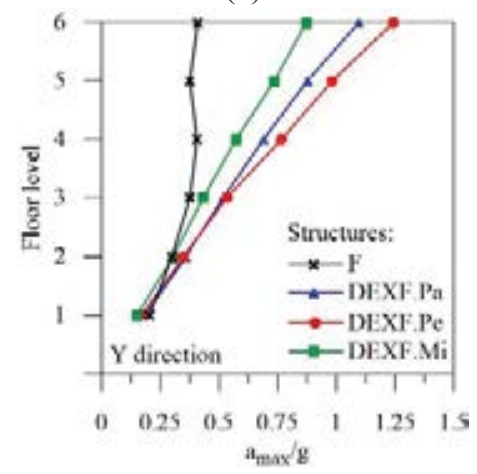

(f)

Figure 12. Global response parameters of the original (F) and retrofitted (DEXF) structures over the elevation. 
With a view to analysing how different configurations of the exoskeleton (i.e. DEX.Pa, DEX.Pe and DEX.Mi) have an impact on the effectiveness of FVDs, the mean of the maximum values of the total damping force at different storeys are shown in Figure 13. As confirmed experimentally [17], the efficiency of the FVDs in the top storey is reduced by at least half of that at the intermediate levels where maximum values are attained, thereby highlighting that a distribution of damping constants proportional to the storey shear represents an efficient design criterion. The highest energy dissipation corresponds to DEX.Pa and DEX.Pe in the X (Figure 13a) and Y (Figure 13e) directions, respectively, but this does not correspond to significant advantages for the DEX.Pe characterized by the additional mass of balconies. It should be noted that total damping force is only divided between two FVDs for DEX.Pa (Figure 13d) and DEX.Mi (Figure 13f) along the Y direction, thus reducing structural redundancy, contrary to DEX.Pe which instead provides four FVDs at each level (Figure 13e), while all solutions ensure the same number of FVDs in the X direction.

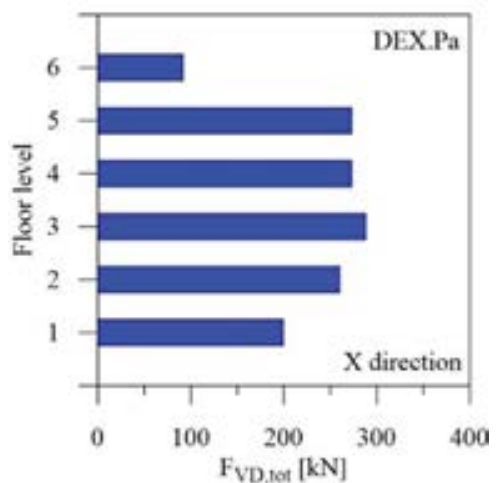

(a)

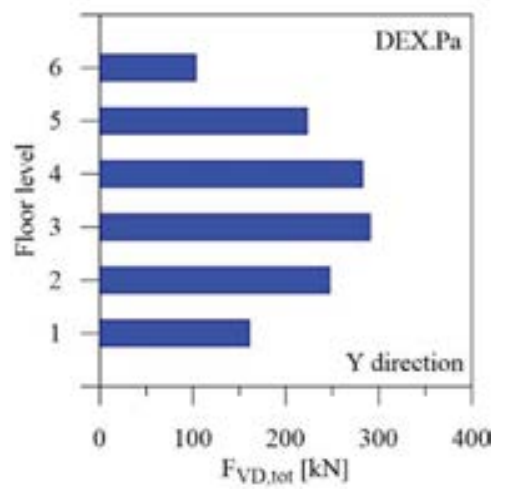

(d)

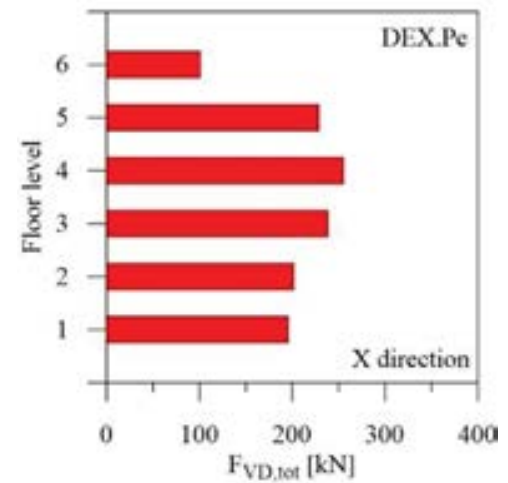

(b)

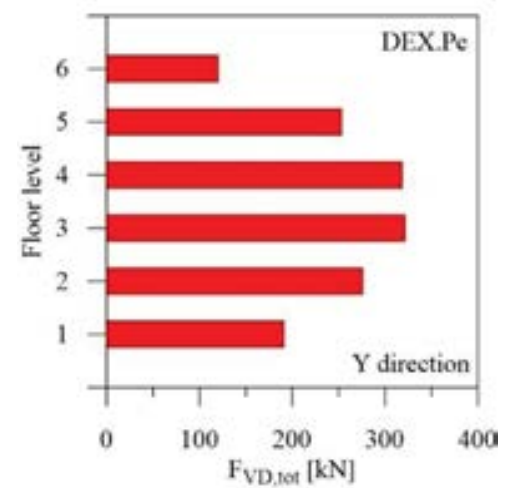

(e)

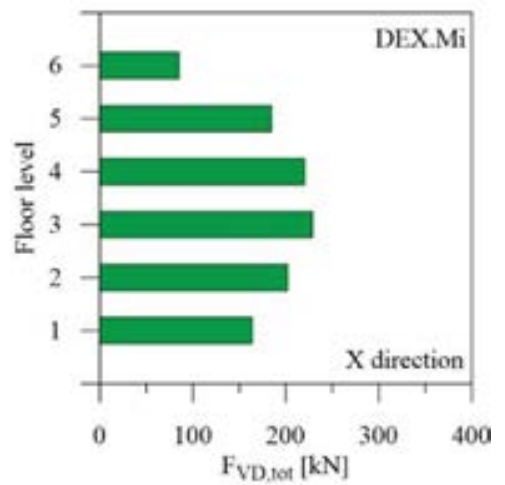

(c)

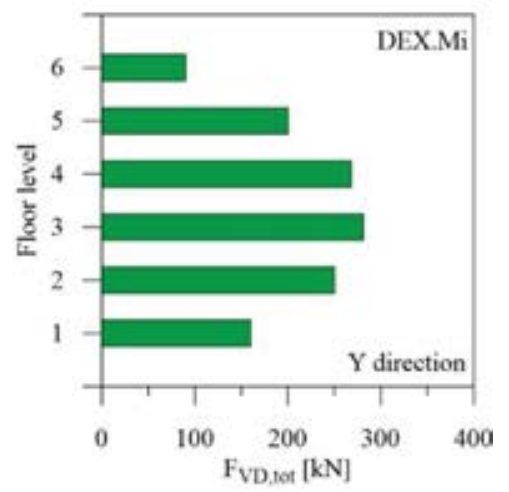

(f)

Figure 13. Distribution of the total damping force of FVDs over the elevation of the DEXs.

\section{CONCLUSIONS}

Pros and cons of the seismic retrofitting of RC buildings by means of dissipative exoskeletons is investigated. To this end, a practical procedure for the seismic design is proposed and developed, in such a way as to make a distinction between the steel exoskeleton and the dissipative bracing system. It is based on the rigid coupling of two SDOF systems equivalent to the original frame and dissipative exoskeleton, respectively, assuming elastic behaviour of steel exoskeleton and nonlinear FVDs. A six-storey RC framed structure located in L'Aquila is assumed as an archetype of the residential housing stock built in Italy during the 1990s, designed for medium-risk seismic zone. Three configurations of the DEX along the perimeter are chosen for retrofitting the original building, assuming elastic behaviour as performance 
objective in a high risk-seismic zone: i.e. DEX.Pa, representing an envelope parallel to all façades; DEX.Pe, perpendicular to all façades; DEX.Mi, suggested as a compromise solution in which DEX.Pa and DEX.Pe are only placed on the sides without apertures. By carrying out nonlinear seismic analysis the following conclusions can be drawn.

The proportion between base shear demands corresponding to $\mathrm{DEX}(\mathrm{F})$ and $(\mathrm{DEX}) \mathrm{F}$ structural parts matches well with the design value of the stiffness ratio, thus confirming the reliability of the proposed design procedure. Moreover, global and local confirmation of the effectiveness of the seismic retrofitting techniques can be drawn from the base shear and interstorey drift demands to (DEX)F, respectively, whose values are less than half of those corresponding to the original frame. The efficiency of the FVDs is confirmed at the lower and intermediate levels while it is reduced in the top storey, thereby highlighting that a distribution of damping constants proportional to the storey shear represents a good design criterion. DEXF.Pa and DEX.Mi appear the best choice parallel to X and Y, respectively, when drift ratios are considered. As expected, the top displacement target value is frequently exceeded by the building in its original condition, but it is sometimes exceeded when retrofitting with DEX.Pe, while DEXF.Pa and DEXF.Mi are always within the limits of this threshold. However, all DEXs induce amplification of the acceleration towards the upper levels of the original building and this may represent a potential risk in the case of acceleration-sensitive nonstructural components.

\section{ACKNOWLEDGEMENTS}

The present work was financed by Re.L.U.I.S. (Italian network of university laboratories of earthquake engineering), in line to the Convenzione D.P.C.-Re.L.U.I.S. 2019-2021, WP15, Code Revisions for Isolation and Dissipation.

\section{REFERENCES}

[1] Z. Liang, G.C. Lee, G.F. Dargush, J. Song, Structural damping: application in seismic response modification. CRC Press, Boca Raton, 2012.

[2] C. Christopoulos, A. Filiatrault, Principles of passive supplemental damping and seismic isolation. IUSS Press, Pavia, Italy, 2006.

[3] A. Marini, C. Passoni, A. Belleri, F. Feroldi, M. Preti, G. Metelli, P. Riva, E. Giuriani, G. Plizzari, Combining seismic retrofit with energy refurbishment for the sustainable renovation of RC buildings: a proof of concept. European Journal of Environmental and Civil Engineering, 1-21, 2017

[4] A. Reggio, L. Restuccia, L. Martelli, G.A. Ferro, Seismic performance of exoskeleton structures. Engineering Structures, 198, 109459, 2019.

[5] G. Di Lorenzo, E. Colacurcio, A. Di Filippo, A. Formisano, A. Massimilla, R. Landolfo, State-of-the-art on steel exoskeletons for seismic retrofit of existing RC buildings. Ingegneria Sismica, 37(1), 33-50, 2020.

[6] A. Caverzan, M. Lamperti Tornaghi, P. Negro (editors). Proceedings of SAFESUST Workshop. A roadmap for the improvement of earthquake resistance and eco-efficiency of existing buildings and cities. Joint Research Centre, Ispra, November 26-27, 2015.

[7] F. Mazza, A. Vulcano, Design of hysteretic damped braces to improve the seismic performance of steel and RC framed structures. Ingegneria Sismica, 31(1), 5-16, 2014. 
[8] F. Mazza, Seismic vulnerability and retrofitting by damped braces of fire-damaged RC framed buildings. Engineering Structures, 101, 179-192, 2015.

[9] F. Mazza, Nonlinear seismic analysis of unsymmetric-plan structures retrofitted by hysteretic damped braces. Bulletin of Earthquake Engineering, 14(4), 1311-1331, 2016.

[10] F. Mazza, A plastic-damage hysteretic model to reproduce strength stiffness degradation. Bulletin of Earthquake Engineering, 17(6), 2787-2819, 2019.

[11] F. Mazza, A simplified retrofitting method based on seismic damage of a SDOF system equivalent to a damped braced building. Engineering Structures, 200, 109712, 2019.

[12] P. Ricci, V. Manfredi, F. Noto, M. Terrenzi, M.T. De Risi, M. Di Domenico, G. Camata, P. Franchin, A. Masi, F. Mollaioli, E. Spacone, G.M. Verderame, RINTC-E: towards seismic risk assessment of existing residential reinforced concrete buildings in Italy. Procs. of the $8^{\text {th }}$ ECCOMAS Thematic Conference on Computational Methods in Structural Dynamics and Earthquake Engineering COMPDYN 2019, Crete, Greece, 24-26 June 2019.

[13] F. McKenna, G.L. Fenves, M.H. Scott. Open system for earthquake engineering simulation. University of California, Berkeley, CA, 2000.

[14] H.M. Dwairi, M.J. Kowalsky, J.M. Nau, Equivalent damping in support of direct displacement-based design. Journal of Earthquake Engineering, 11(4), 512-530, 2007.

[15] Y.-Y. Lin, K.-C. Chang, C.-Y. Chen, Direct displacement-based design for seismic retrofit of existing buildings using nonlinear viscous dampers. Bulletin of Earthquake Engineering, 6(3), 535-552, 2008.

[16] F. Mazza, M. Mazza, A. Vulcano, Displacement-based seismic design of hysteretic damped braces for retrofitting in-elevation irregular RC framed structures. Soil Dynamics and Earthquake Engineering, 69, 115-124, 2015.

[17] G. Pekcan, J.B. Mander, S.S. Chen, Design and retrofit methodology for building structures with supplemental energy dissipating systems. Report No. MCEER-99-0021. New York at Buffalo, 1999.

[18] J.-S. Hwang, W.-C. Lin, N.-J. Wu, Comparison of distribution methods for viscous damping coefficients to buildings. Structure and Infrastructure Engineering: Maintenance, Management, Life-Cycle Design and Performance, 9(1), 28-41, 2013.

[19] DM96, Italian Building Code 86. Norme tecniche relative alle costruzioni antisismiche. DM 24-01-1986, Italian Ministry of Public Works, Rome, Italy.

[20] DM92, Italian Building Code 92. Norme tecniche per le opere in c.a. normale e precompresso e per le strutture metalliche. DM 14-02-1992, Italian Ministry of Public Works, Rome, Italy.

[21] L.F. Ibarra, R.A. Medina, H. Krawinkler, Hysteretic models that incorporate strength and stiffness deterioration. Earthquake Engineering and Structural Dynamics, 34(12), 1489-1511, 2005.

[22] F. Mazza, Modelling and nonlinear static analysis of reinforced concrete framed buildings irregular in plan. Engineering Structures, 80, 98-108, 2014. 
[23] S, Alath, S.K. Kunnath, Modeling inelastic shear deformation in RC beam-column joints. Proceedings of the 10 $0^{\text {th }}$; Conference in Engineering Mechanics, University of Colorado at Boulder, Colorado, 1995.

[24] F. Mazza, Shear modelling of the beam-column joint in the nonlinear static analysis of RC framed structures retrofitted with damped braces. Bulletin of Earthquake Engineering, 108, 111-129, 2018.

[25] NTC18, Italian Building Code 18. Norme tecniche per le costruzioni. DM 17-01-2018, Italian Ministry of Infrastructures and Transports, Rome, Italy.

[26] L. Luzi, S. Hailemikael, D. Bindi, F. Pacor, F. Mele, F. Sabetta, ITACA (ITalian ACcelerometric Archive): a web portal for the dissemination of Italian strong-motion data, Seismol. Res. Lett., 79, 716-722, 2008.

[27] T.D. Ancheta, R.B. Darragh, J.P. Stewart, E. Seyhanb, W.J. Silva, B. Chiou, K. Wooddell, R. Graves, A.R. Kottke, D. Boore, T. Kishida, J. Donahue, NGA-West2 database. Earthquake Spectra, 30(3), 989-1005, 2014.

[28] I. Iervolino, A. Spillatura, P. Bazzurro, Seismic structural reliability of code-conforming Italian buildings. Journal of Earthquake Engineering, 22, 5-27, 2018. 